\title{
INTERIOR OF BEDROOM FROM ANCIENT TO MODERN ERA
}

\author{
Dr. Mrs. Nanadini Rekhade \\ Professor Home science Department \\ Govt M.L.B Girls P.G College, Indore
}

\section{INTRODUCTION}

Bedrooms are the primary place of relaxation, where we all retire to take a good sleep and refresh, away from the world and worries. The bedroom interior design is extremely important in order to provide that instant feel of relaxation and here are a few tips: the first thing that meets the eyes are the colors used on the walls, carpets and bed set so, they all must be soothing in pastel colors in order to provide a relaxing effect.

\section{ANCIENT BEDROOMS}

We had the view into the opulent and over-decorated Bedrooms of the Royals and their beds which might not have been as comfortable as they looked like first hand - now we have a peek into the bedrooms and beds of people who lived many centuries ago. Some of them must have been quite comfortable with the appropriate bedding but then, thinking of the hygiene in these times, makes feel shiver. In ancient times people never thought about good designing, people just wanted things to look shining hence, that time people were not that aware of designing the rooms in a proper manner.

\section{MODERN BEDROOM}

Keep the bedroom interior design minimal, neat and always clean but also don't forget to add some change and color with every season in order to keep it exciting and adventurous. Changing your bedroom interior design should only be done to suit an occasion or festivity as constant major changes will actually induce restlessness instead of relaxation until you get used to the sight and sounds and once again be able to relax and enjoy your bedroom interior design. Now a days people want the rooms to be less decorated and give a charming look which suites their demands a lot and that's why people decorate their rooms according to their use of rooms and also according to the personality which is going to use that room.

\section{OBJECTIVES FOR DESIGNING A BEDROOM}

- To execute a lovely look for the bedroom.

- Give a hygienic and relaxing environment to the bedroom.

- Evaluate light and I schemes for bedrooms.

- To obtain a exhautic look and feel for a human being according to the personality of one.

- Evaluate space plan in bedroom.

\section{VARIETIES OF BEDROOM}




\section{ROMAN BEDROOM}

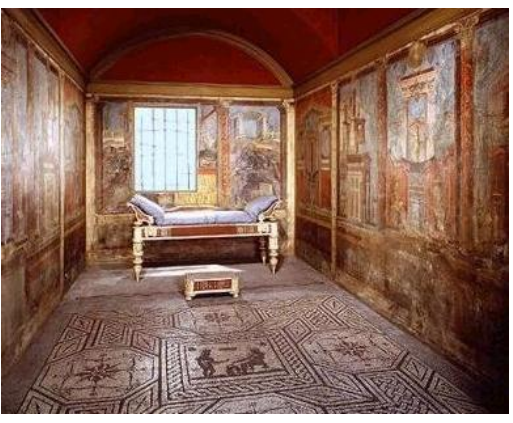

Cubicula were small rooms used for a number of different purposes; on the upper story and in the interior of the house they often functioned as bedrooms, while the small rooms off the atrium may have been used for private meetings, libraries, etc. While the bedroom above, from the Villa at Boscoreale, has wonderfully detailed wall paintings designed to make the room appear more open and spacious, many cubicula were decorated more simply. This rooms were mainly used for sitting purpose and resting purpose not for bedding time.

\section{CHINESE BEDROOM}

"In ancient time, bed is a piece of furniture for people to sit and lie on, as was different from the modern bed, which is used solely for sleeping. In Paraphrasing Texts and Words, "Bed refers to a seat for one to settle down." Settling down just means making one's body feel secure and comfortable, thus bed can refer to anything that plays a supporting and steadying function. These type of rooms were used by single purpose to enjoy their singleness and

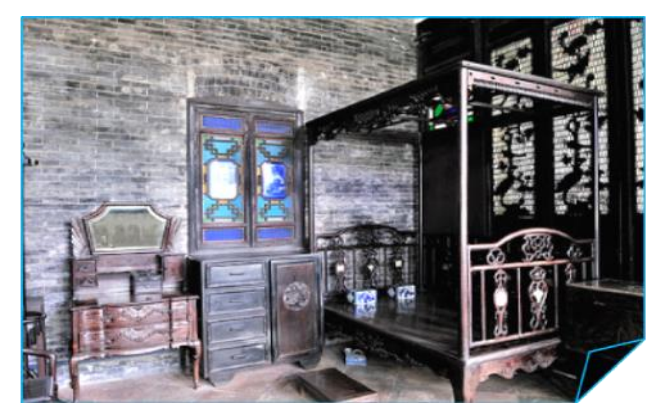
live their own style.

\section{INDIAN BEDS AND BEDROOMS}

We know that India has a long tradition of arts and crafts and can look back on many centuries of some of the most sophisticated cultures on this planet. The images certainly do not represent an ancient Indian environment but are rather replicas - nevertheless the designs have not changed much in the past centuries.Therefore I have added images from a wonderful and extremely inspirational blog "An Indian Summer" from Bhavna, an Indian consultant from Gurgaon in India. The blog is full of ideas of Indian inspired rooms and bedrooms - all of them very beautiful and inspirational, from traditional to modern touches.

\section{MODERN BEDROOM}

Keep the bedroom interior design minimal, neat and always clean but also don't forget to add some change and color with every season in order to keep it exciting and adventurous. Changing your bedroom interior design should only be done to suit an occasion or festivity as constant major changes will
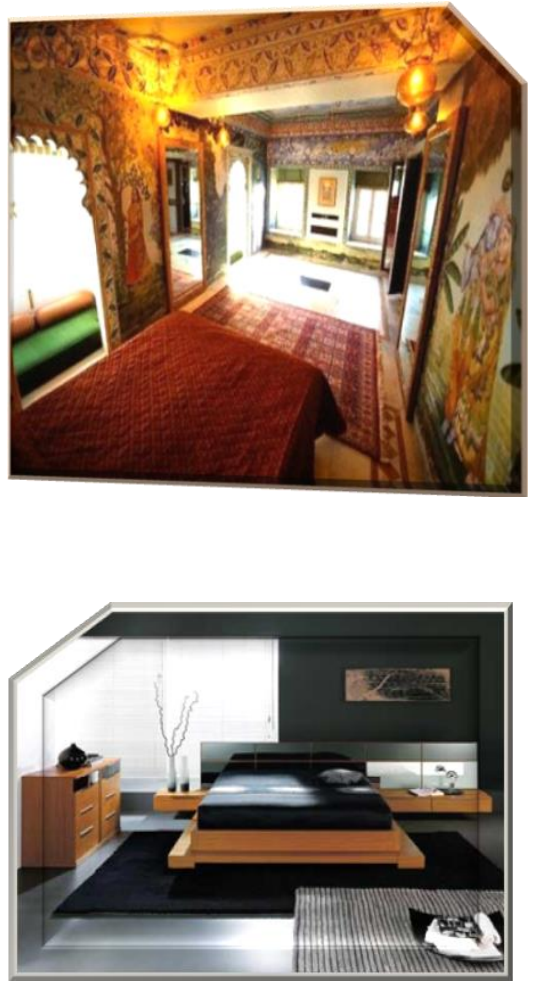


\section{INTERNATIONAL JOURNAL Of RESEARCH -GRANTHAALAYAH \\ A knowledge Repository}

Art

actually induce restlessness instead of relaxation until you get used to the sight and sounds and once again be able to relax and enjoy your bedroom interior design. This is a room which is giving a typical professional look for couples and and working individual who love to relax after a tough job of full day.

\section{CHANGES IN BEDROOM}

- From bed sheets to linen.

- Curtains selection.

- Decorum for furniture and fixtures.

- Carpet designs.

- Flower decoration.

- Wallpapers designs.

- Tiles selection.

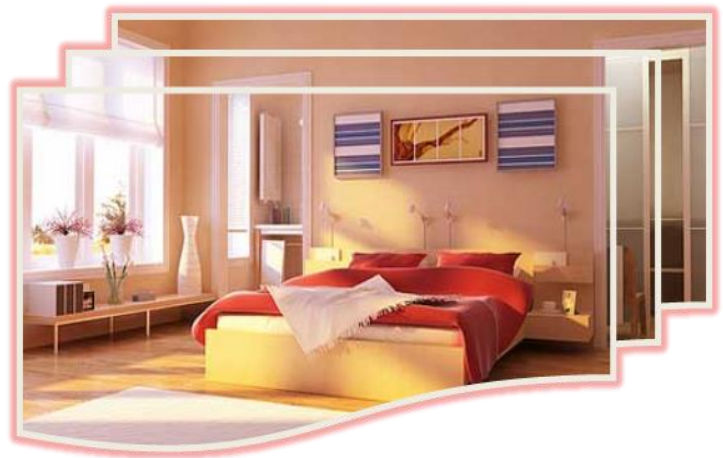

- Dressing room decorations with the dressing table.

- Color combination of rooms according to the age group of persons using the room.

- Interior should be according to the theme of the room setup.

\section{CURRENT TRENDS}

A WALL DECAL, also known as a wall sticker, wall tattoo, or wall vinyl, is a vinyl sticker that is affixed to a wall or other smooth surface for decoration and informational purposes. Wall decals are cut with vinyl cutting machines. Most decals use only one color, but some may have various images printed upon them.

\section{SOME IMAGES OF WALL DECAL/STICKERS}
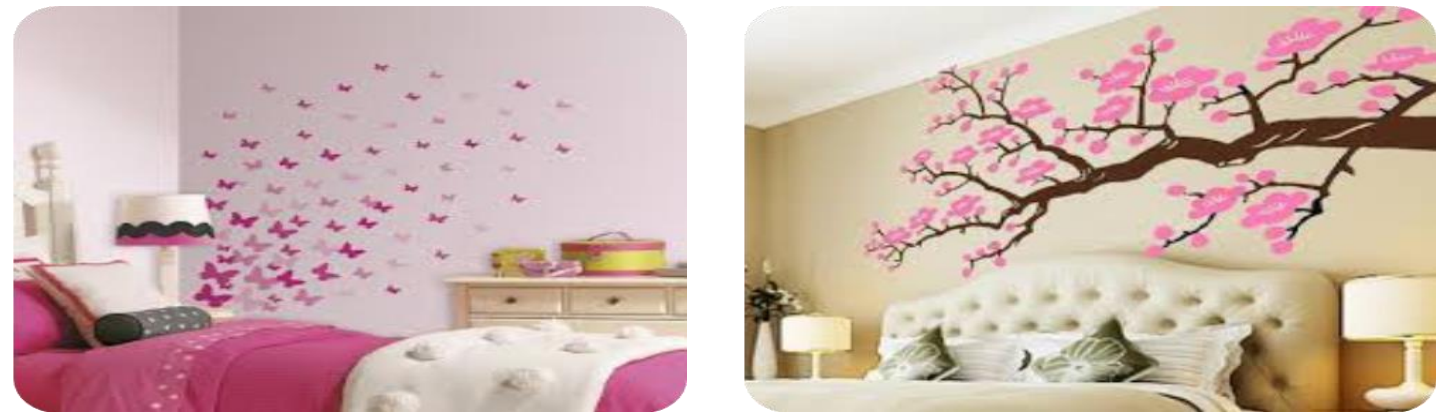

\section{EMOTIONAL EFFECT OF COLOURS}




\section{INTERNATIONAL JOURNAL Of RESEARCH -GRANTHAALAYAH

\section{PROPERTIES OF COLOR}

RED: Being the longest wavelength, red is a powerful color. Although not technically the most visible, it has the property of appearing to be nearer than it is and therefore it grabs our attention first. Hence its effectiveness in traffic lights the world over. Its effect is physical; it stimulates us and raises the pulse rate, giving the impression that time is passing faster than it is. It relates to the masculine principle and can activate the "fight or flight" instinct. Red is strong, and very basic. Pure red is the simplest colour, with no subtlety. It is stimulating and lively, very friendly. At the same time, it can be perceived as demanding and aggressive.

BLUE: Blue is the colour of the mind and is essentially soothing; it affects us mentally, rather than the physical reaction we have to red. Strong blues will stimulate clear thought and lighter, soft blues will calm the mind and aid concentration. Consequently it is serene and mentally calming. It is the colour of clear communication. Blue objects do not appear to be as close to us as red ones. Time and again in research, blue is the world's favourite colour. However, it can be perceived as cold, unemotional and unfriendly.

YELLOW: The yellow wavelength is relatively long and essentially stimulating. In this case the stimulus is emotional, therefore yellow is the strongest colour, psychologically. The right yellow will lift our spirits and our self-esteem; it is the colour of confidence and optimism. Too much of it, or the wrong tone in relation to the other tones in a colour scheme, can cause self-esteem to plummet, giving rise to fear and anxiety. Our "yellow streak" can surface.

GREEN: Green strikes the eye in such a way as to require no adjustment whatever and is, therefore, restful. Being in the centre of the spectrum, it is the colour of balance - a more important concept than many people realise. When the world about us contains plenty of green, this indicates the presence of water, and little danger of famine, so we are reassured by green, on a primitive level. Negatively, it can indicate stagnation and, incorrectly used, will be perceived as being too bland.

VOILET: The shortest wavelength is violet, often described as purple. It takes awareness to a higher level of thought, even into the realms of spiritual values. It is highly introvertive and encourages deep contemplation, or meditation. It has associations with royalty and usually communicates the finest possible quality. Being the last visible wavelength before the ultraviolet ray, it has associations with time and space and the cosmos. Excessive use of purple can bring about too much introspection and the wrong tone of it communicates something cheap and nasty, faster than any other colour.

ORANGE: Since it is a combination of red and yellow, orange is stimulating and reaction to it is a combination of the physical and the emotional. It focuses our minds on issues of physical comfort - food, warmth, shelter etc. - and sensuality. It is a 'fun' colour. Negatively, it might focus on the exact opposite - deprivation. This is particularly likely when warm orange is used with black. Equally, too much orange suggests frivolity and a lack of serious intellectual values. 


\section{INTERNATIONAL JOURNAL Of RESEARCH -GRANTHAALAYAH \\ A knowledge Repository}

Art

PINK: Being a tint of red, pink also affects us physically, but it soothes, rather than stimulates. (Interestingly, red is the only colour that has an entirely separate name for its tints. Tints of blue, green, yellow, etc. are simply called light blue, light greenetc.) Pink is a powerful colour, psychologically. It represents the feminine principle, and survival of the species; it is nurturing and physically soothing. Too much pink is physically draining and can be somewhat emasculating.

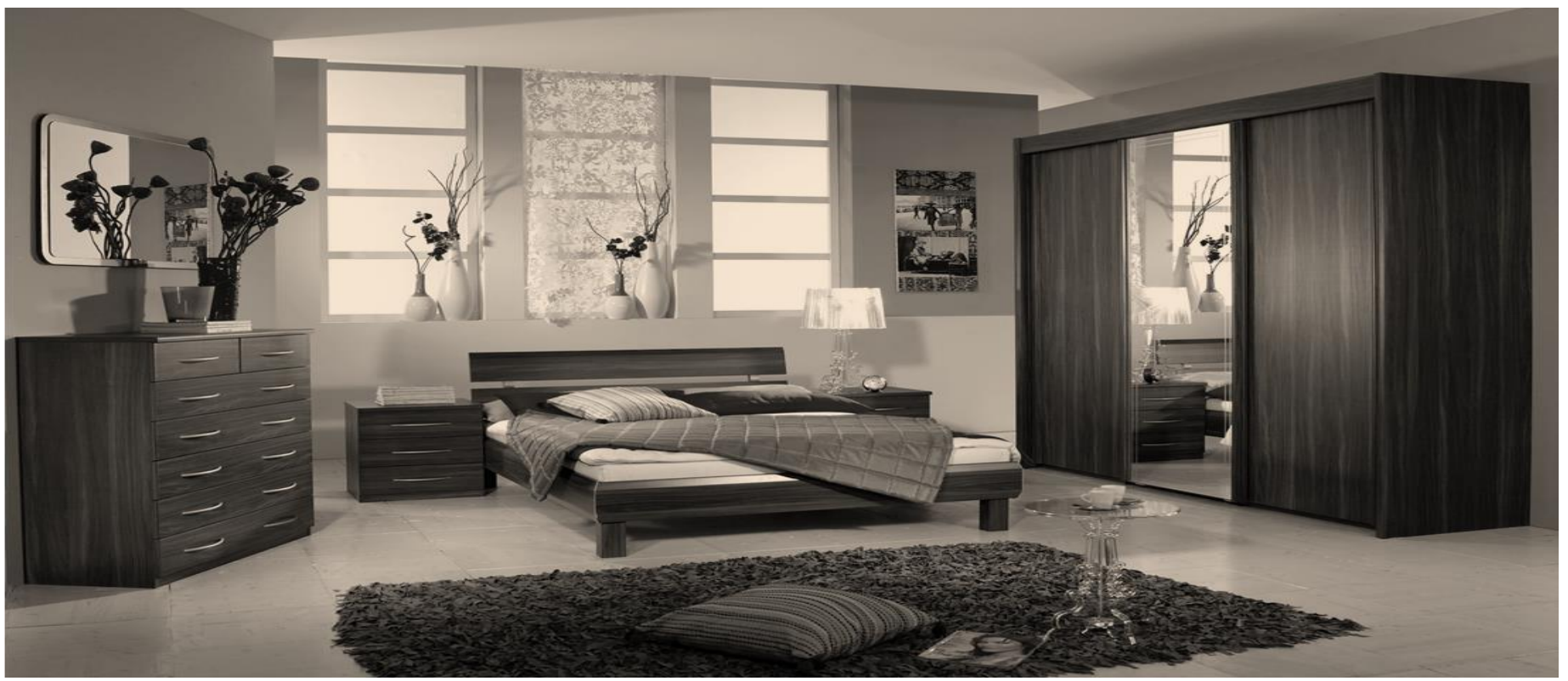

\section{CONCLUSION}

It is seen that be it ancient bedroom or modern bedroom: it is always a dream décor for a human being. A bed room is a way to forget all worries and dive into the love of theme, color, designs, linen, etc. A particular human should keep all those matters in mind and then design a room so that once it is designed you enjoy the ambience of your DREAM ROOM.

\section{REFERENCE}

1 http://freshome.com/2008/02/07/bedroom-interior-design/

2 http://artandinterior.blogspot.in/2012/04/special-series-ancient-beds-and.html

3 http://artandinterior.blogspot.in/2012/04/special-series-ancient-beds-and.html

4 Elements of Style: Designing a Home \& a Life by Erin Gates

5 Jean-Louis Deniot: Interiors by Diane Dorrans Saeks and Xavier Bejot 